\title{
CONCEPTS
}

\section{Concussion Management in the Wilderness}

\author{
Justin M. Wright, MD; Arthur A. Islas, MD, MPH \\ From the Department of Family and Community Medicine, Paul L. Foster School of Medicine, Texas Tech University Health Sciences Center, \\ El Paso, TX.
}

\begin{abstract}
Head trauma accounts for a significant number of injuries in the wilderness setting. Concussions are possible sequelae of falls or encounters with unforeseen obstacles. Although not immediately lifethreatening, concussions can be a source of significant short- and long-term morbidity. Diagnosis of a concussion in the wilderness may be challenging as symptoms can often be confused with other conditions, such as altitude illness and hyponatremia. Successful management depends on accurate diagnosis and determination of the severity of symptoms so that appropriate decisions regarding treatment and need for evacuation can be made.
\end{abstract}

Key words: concussion, head injury, wilderness

\section{Introduction}

On playing fields across the country, athletic trainers and team physicians treat athletes who have suffered concussions. It is an entity whose management has changed dramatically during the last decade. Even with the new changes in management and in the relatively controlled environment of the athletic arena, concussions present a significant challenge to healthcare providers as it is an entity that can be difficult to diagnose and challenging to treat in a patient population that is driven and goaloriented. But what happens when a concussion is sustained in the wilderness? With the unforeseen obstacles and dangers present in the austere environment, the potential for one to suffer a concussion is high and the ability to manage a concussion is ever more challenging given limited resources and distance from definitive care.

A concussion is a brain injury, a disturbance in brain function induced by traumatic forces, either from a direct blow to the head or a transmitted force from a blow to the body. ${ }^{1,2}$ Traumatic forces induce a neurometabolic cascade of events, starting with a disruption of neuronal cell membranes, efflux of potassium ions, and widespread neurotransmitter release, leading to more potassium efflux. To restore homeostasis, membrane ionic

Corresponding author: Justin M. Wright, MD, Department of Family and Community Medicine, Paul L. Foster School of Medicine, Texas Tech University Health Sciences Center, 9849 Kenworthy Street, El Paso, TX 79924 (e-mail: justin.wright@ttuhsc.edu). pumps are activated, consuming ATP and leading to hyperglycolysis to keep up with energy production. Energy depletion and resulting glucose hypometabolism follow within 6 hours of the injury. Concurrently, trauma-induced $N$-methyl-D-aspartate (NMDA) channel activation results in calcium ion accumulation in the mitochondria, causing glucose oxidative dysfunction. This combination of glucose hypometabolism and impaired oxidative metabolism contributes to the symptoms of concussion, and may last from 5 to 10 days. ${ }^{3}$

If properly managed, those who experience a concussion will recover completely without long-term sequelae. Improperly managed or unrecognized concussions may lead to prolonged physical and psychological symptoms. The wilderness setting is often remote, with limited supplies, weather and climate factors, and a potential lack of shelter, time to rescue or evacuation challenges, and innate topographical and geographical circumstances that are not necessarily stable and controllable as in an urban setting. Wilderness sport participation may take place as sanctioned wilderness races or sporting events with medical tents and trained personnel, or they may be individual recreational events or commercially guided trips or expeditions with little ability for intervention if an injury or emergency takes place. As such, wilderness practitioners must be prepared to recognize and manage concussion in a variety of settings. In an extensive review of the literature, we found few or no articles on concussion management for the wilderness environment. The aim of this review is to 
introduce the topic of concussion and discuss its management as it pertains to wilderness areas.

\section{Epidemiology}

Among the athletic population, the incidence of concussion is estimated to be 1.6 to 3.8 million annually. ${ }^{1,4}$ In the wilderness setting, the incidence is not as clear. Overall occurrence of injury has been reported to be low. ${ }^{5-13}$ In studies that examined injury and illness among national park visitors, head injury in the wilderness has been reported to comprise $3.3 \%$ to $34.8 \%$ of all injuries sustained. ${ }^{5,6,10-13}$ Among students in the National Outdoor Leadership School (NOLS), head injuries are responsible for between $2.0 \%$ and $4.1 \%$ of all injuries. ${ }^{7-9}$ Reports of injuries involving mountain and wilderness sports list an incidence of $6 \%$ to $29 \%$ of all injuries. ${ }^{4,14,15}$ However, many of these studies grouped concussion with other types of head injuries, making it difficult to determine a true prevalence. Studies that looked at specific activities suggest that concussions account for $6.5 \%$ of injuries from outdoor activities presenting to emergency departments, ${ }^{6} 1.2 \%$ of injuries occurring in mountain bike racers, ${ }^{15} 9.6 \%$ of all injuries in skiers, ${ }^{4} 14.7 \%$ of all injuries in snowboarders, ${ }^{4}$ and $5.7 \%$ of all injuries in snowbladers. ${ }^{4}$ It is difficult to obtain a true incidence of concussion in the wilderness because recognition can often be difficult and many do not seek medical attention until returning home. Previous outdated definitions and grading systems may have also led to inaccurate or absent reporting of concussions in previous injury incidence studies.

\section{Evaluation}

Whether in a controlled setting or a remote austere environment, the recognition and initial evaluation of concussion is the same. After head trauma, one must first evaluate for life-threatening injury. The ABCs (airway, breathing, circulation) should be assessed, and the patient should be evaluated for cervical spine injury and skull fracture and treated per ATLS (Advanced Trauma Life Support) guidelines. Complaints of neck pain, limited range of motion, significant spinal tenderness, or numbness or tingling in the extremities should prompt concern for a cervical spine injury. The unconscious patient should also arouse suspicion for a much more serious affliction. If a cervical spine injury or skull fracture is suspected, the patient should be stabilized and transported according to the Wilderness Medical Society guidelines for spine immobilization. ${ }^{16}$ Once these conditions have been reasonably ruled out, the neurocognitive evaluation can proceed. Several concussion tools are available, including the SAC (Standardized Assessment of Concussion) and the SCAT-3 (Sideline Concussion Assessment Tool 3). ${ }^{1,2}$ Although these tools are used frequently on the sidelines during athletic competition, their inclusion in preparations for wilderness excursions may not be practical.

\section{SYMPTOMS}

Initial steps in evaluating a concussion include recognition of and questioning about the presence of symptoms. Headache is the most common presenting symptom of a concussion. ${ }^{1}$ The patient may also complain of dizziness, balance disturbance, or disorientation. Photophobia, phonophobia, amnesia, and nausea may be present as well. Loss of consciousness, once considered necessary for the diagnosis of concussion, occurs infrequently and, unless prolonged ( $>1$ minute), is not indicative of the severity of the injury. ${ }^{1,17}$ Many patients also report temperament changes or emotional lability or may complain of a feeling of fogginess and an inability to focus or concentrate. Family members, friends, and other associates may also note personality changes. Patients may have one or any number of the symptoms listed above, and the number or severity of symptoms may not correlate to injury severity or length of time to recovery ${ }^{1,2}$

\section{ORIENTATION}

It is well documented that the standard orientation questions of person, place, and time have been shown to be unreliable in an athletic situation when compared with other memory assessments. ${ }^{2}$ Maddocks et al $^{18}$ developed a series of questions relevant to the sport that are more reliable in determining an athlete's orientation. These questions can be modified to reflect the wilderness setting (Table 1). Attention should also be paid to how quickly the patient responds. A failure to correctly answer these questions or taking longer to answer than expected may indicate that the patient has suffered a concussion. ${ }^{17,18}$

\section{EXAMINATION}

The examiner should perform a physical examination, focusing on the neurological examination and balance. Cranial nerves should be assessed, with any focal neurologic signs signaling a discrete intracranial lesion. ${ }^{1}$ Pupils may be sluggish to react to light but should be equal bilaterally. Unequal pupils may also indicate a discrete lesion. ${ }^{1}$ Attention should be paid to the individual with unequal pupil sizes at baseline. Balance may be assessed using the Romberg test or by observing 
Table 1. Questions to assess orientation

\begin{tabular}{ll}
\hline \multicolumn{1}{c}{ Maddocks $^{18}$} & \multicolumn{1}{c}{ Modified Maddocks } \\
\hline $\begin{array}{l}\text { At which ground (field) } \\
\text { are we? }\end{array}$ & Where are we? \\
$\begin{array}{l}\text { What quarter is it? } \\
\text { How far into the quarter }\end{array}$ & How did we get here? \\
is it? & Who is in the group with us? \\
$\begin{array}{l}\text { Which side kicked the } \\
\text { last goal? }\end{array}$ & Where did we hike yesterday? \\
$\begin{array}{l}\text { Which team did we play } \\
\text { last week? }\end{array}$ & Where were we planning to \\
Did we win last week? & hike tomorrow? \\
\hline
\end{tabular}

the patient's heel-to-toe, or tandem, gait. The patient walks forward in a straight line, touching heel to toe with each step. The patient fails the test if they step off the line, have a separation between their heel and toe, or if they touch or grab the examiner or an object. ${ }^{2}$ Care should be taken to assess balance in a safe area on level ground, with the examiner nearby to catch the patient should he or she fall. In addition, other neurologic examinations should be performed to assess concentration and immediate and short-term recall such as serial sevens, naming and repeating 3 objects, spelling the word world backward, or reciting the months of the year in reverse order.

\section{Differential Diagnosis}

Absent a witnessed head trauma, the symptoms of concussion may be confused for many other entities. A list of conditions that may be confused for concussion in the wilderness is listed in Table 2. Specifically, the signs and symptoms of concussion overlap with two of the more commonly discussed wilderness medicine topics, acute mountain sickness (AMS) and exercise-associated hyponatremia $(\mathrm{EAH})$

Table 2. Entities that may be confused for concussion

Acute mountain sickness (AMS) or high altitude cerebral
edema (HACE)
Carbon monoxide poisoning
CNS infections
Dehydration
Exercise-associated hyponatremia (EAH)
Gastrointestinal illness
Intracranial bleed
Other intoxications or poisonings
Sleep deprivation
Upper respiratory infection or sinusitis

CNS, central nervous system.
Acute mountain sickness is a failure to acclimatize to the low partial pressure of oxygen at high altitude and may be a consequence of rapid ascent. Acute mountain sickness presents with headache, insomnia, dizziness, anorexia, and nausea. The headache often worsens with exertion. Acute mountain sickness may progress to high altitude cerebral edema (HACE) with the development of altered mental status, including confusion, drowsiness, stupor, and ataxia. ${ }^{19,20}$ The severity of AMS can be scored by the Lake Louise Questionnaire, which gives a score based on the severity of the following symptoms: headache, gastrointestinal symptoms, fatigue or weakness, dizziness or lightheadedness, difficulty sleeping, change in mental status, ataxia, and peripheral edema. ${ }^{21}$ In patients with AMS or HACE, immediate descent, supplemental oxygen, portable hyperbaric chambers, and the medications acetazolamide and dexamethasone have all been shown to be effective treatment options. ${ }^{22}$ When approaching a patient at altitude with these symptoms, it is reasonable to treat as though they have AMS. However, these treatments would not be expected to rapidly improve the symptoms of a patient with concussion.

Exercise-associated hyponatremia develops during or up to 24 hours after prolonged periods of exertion because of a combination of excessive fluid intake and impaired urinary water excretion. Symptoms of EAH also overlap with those of concussion, including headache, dizziness, confusion, and nausea. ${ }^{23,24}$ Exerciseassociated hyponatremia may also present with swollen extremities or signs and symptoms of pulmonary edema, which would not be expected in concussion. Treatment includes fluid restriction until the patient is able to urinate in mild cases and hypertonic saline boluses in severe cases. ${ }^{23}$ These measures would not be expected to improve the symptoms in a patient with a concussion.

\section{Acute Management}

In the management of a concussed patient in the wilderness, the decision to evacuate versus treat in the field depends on the extent and character of the symptoms as well as the distance from medical assistance.

Although most concussions do not require imaging, many symptoms that accompany a concussion may indicate a more severe lesion and necessitate an imaging study. The decision to evacuate immediately may be extrapolated from published guidelines regarding the management of closed head injuries, in which satisfying the indications for imaging may denote a more serious injury. Therefore, in an adult patient (older than 16 years of age) who suffers a head injury, evacuation should be 
considered with loss of consciousness, severe headache, repetitive vomiting, age older than 60 years, alcohol or drug intoxication, posttraumatic seizure, a Glasgow Coma Scale of less than 15 (eyes not opening spontaneously, not following commands, not oriented), a focal neurologic deficit, or in a patient with a coagulopathy, signs of a basilar skull fracture, or a fall from height greater than $1 \mathrm{~m}$ (3 feet) resulting in head injury. ${ }^{25} \mathrm{In}$ a child (2-20 years of age) with a head injury, evacuation should be considered in those who experience loss of consciousness (especially greater than 60 seconds), have evidence of a skull fracture, or have focal neurologic findings on examination. ${ }^{26}$ These symptoms, as described above for adults and children respectively, should prompt a call for aid in evacuating the patient as expeditiously as possible. These guidelines contain an age overlap between ages 16 and 20. If a patient falls within this age overlap, clinical judgment should be used to determine which guideline to follow.

The hallmark of concussion management is absolute rest from physical and mental stimulation followed by gradual return to activity once symptoms resolve. ${ }^{2}$ Excessive exertion of a concussed brain may worsen symptoms and lead to a prolonged recovery. Therefore, the geographical location where the injury occurred also factors into the decision to evacuate and how to evacuate. Protocols for return to play in sports exist, but may not apply to the wilderness setting. For concussions that occur within an easy day's travel back to a base where rest and care can be sought, the patient should attempt to return, provided he or she does not meet the immediate evacuation criteria above and can self-ambulate the route safely. If the decision is made to ground assist the patient back, the patient should be guided out slowly, with frequent stops. Caution should be exercised especially while navigating rough terrain, as there may be a balance disturbance. For those injuries that occur 2 or more days of travel from base and medical attention, the patient should either rest until symptoms improve before moving on or consider calling for help to be extricated from the area. Once the patient has gone 24 hours without symptoms, a modified protocol for return to activity can be instituted, in which the exertion and physical challenge is gradually and incrementally increased over a period of 2 to 3 days until the level of exertion required for the patient to move on or evacuate safely is achieved. If symptoms return during any period of exertion, the individual must rest 24 hours and repeat the last symptom-free activity. An example of this may be light hiking on day 1 , more strenuous hiking on day 2 , and a strenuous hike with a pack on day 3 (Table 3).

\section{WILDERNESS SPORTS}

In coverage of sanctioned wilderness events, any participant suspected of having a concussion should be

Table 3. Return-to-play protocol ${ }^{2}$

\begin{tabular}{|c|c|c|c|c|}
\hline & Rehabilitation stage & $\begin{array}{c}\text { Functional exercise at each } \\
\text { stage of rehabilitation (sports) }\end{array}$ & $\begin{array}{c}\text { Functional exercise at each } \\
\text { stage of rehabilitation } \\
\text { (wilderness) }\end{array}$ & $\begin{array}{c}\text { Objective of each } \\
\text { stage }\end{array}$ \\
\hline 1 & No activity & $\begin{array}{l}\text { Symptom-limited physical and } \\
\text { cognitive rest }\end{array}$ & $\begin{array}{l}\text { Symptom-limited physical } \\
\text { and cognitive rest }\end{array}$ & Recovery \\
\hline 2 & Light aerobic exercise & $\begin{array}{l}\text { Walking, swimming, or cycling, } \\
\text { keeping intensity }<70 \% \\
\text { maximal permitted heart rate } \\
\text { No resistance training }\end{array}$ & $\begin{array}{l}\text { Light hiking without a pack, } \\
\text { keeping intensity }<70 \% \\
\text { maximal permitted heart } \\
\text { rate }\end{array}$ & Increase HR \\
\hline 3 & $\begin{array}{l}\text { Sport-specific } \\
\text { exercise }\end{array}$ & $\begin{array}{l}\text { Skating drills in ice hockey, } \\
\text { running drills in soccer. No } \\
\text { head impact activities }\end{array}$ & $\begin{array}{l}\text { More strenuous hiking } \\
\text { without a pack }\end{array}$ & Add movement \\
\hline 4 & $\begin{array}{l}\text { Noncontact training } \\
\text { drills }\end{array}$ & $\begin{array}{l}\text { Progression to more complex } \\
\text { training drills, eg, passing } \\
\text { drills in football and ice } \\
\text { hockey. May start progressive } \\
\text { resistance training }\end{array}$ & Strenuous hiking with a pack & $\begin{array}{l}\text { Exercise, coordination, } \\
\text { and cognitive load }\end{array}$ \\
\hline 5 & Full-contact practice & $\begin{array}{l}\text { After medical clearance, } \\
\text { participate in normal training } \\
\text { activity }\end{array}$ & N/A & $\begin{array}{l}\text { Restore confidence, } \\
\text { assess function skills } \\
\text { by coaching staff }\end{array}$ \\
\hline 6 & Return to play & Normal game play & & \\
\hline
\end{tabular}

HR, heart rate; N/A, not applicable. 
immediately removed from competition for the remainder of the day and held from competition until that person is asymptomatic. Once the participant is asymptomatic, he or she should undergo a graded exertion program to assess readiness to return to full competition. Competitors looking to return to sports should follow a protocol in which exertion is gradually increased each day until the athlete is able to participate fully without symptoms. After the athlete has successfully completed the protocol, he or she may return to full competition. ${ }^{2}$

\section{Postconcussion Care}

After initiating management in the backcountry and upon safe return from the wilderness, the patient should follow up with a physician knowledgeable in the treatment of concussions. As mentioned above, the treatment of concussion involves physical and cognitive rest. Once back in a controlled or urban setting, patients should be restricted from mentally stimulating activities, including reading, video games, and text messaging. Television and computer use is limited, and patients are usually removed from school or work until symptoms improve. ${ }^{1}$ The transition back to school or work is gradual, often with modifications to allow more time for assignments and testing.

\section{Conclusions}

In the relatively controlled environment of the athletic arena, the diagnosis and management of concussion is challenging, even to the most experienced provider. The uncertainties of the austere environment make management more difficult. However, with proper identification and treatment, combined with awareness of surroundings, concussion can be successfully managed in different wilderness setting, therefore improving outcomes.

\section{Acknowledgements}

We would like to thank Rae Lynn Ortega, MD, for her assistance in the preparation of this manuscript.

\section{References}

1. Scorza KA, Raleigh MF, O'Connor FG. Current concepts in concussion: evaluation and management. Am Fam Physician. 2012;85:123-132.

2. McCrory P, Meeuwisse WH, Aubry M, et al. Consensus statement on concussion in sport: the 4th International Conference on Concussion in Sport held in Zurich, November 2012. Br J Sports Med. 2013;47:250-258.

3. Barkhoudarian G, Hovda DA, Giza CC. The molecular pathophysiology of concussive brain injury. Clin Sports Med. 2011;30(1):33-48, vii-iii.
4. Daneshvar DH, Nowinski CJ, McKee AC, Cantu RC. The epidemiology of sport-related concussion. Clin Sports Med. 2012;30:1-17.

5. Stephens BD, Diekema DS, Klein EJ. Recreational injuries in Washington state national parks. Wilderness Environ Med. 2005;16:192-197.

6. Flores AH, Haileyesus T, Greenspan AI. National estimates of outdoor recreational injuries treated in emergency departments, United States, 2004-2005. Wilderness Environ Med. 2008;19:91-98.

7. McIntosh SE, Leemon D, Visitacion J, Schimelpfenig T, Fosnocht D. Medical incidents and evacuations on wilderness expeditions. Wilderness Environ Med. 2007;18: 298-304.

8. Gentile DA, Morris JA, Schimelpfenig T, Bass SM, Auerbach PS. Wilderness injuries and illnesses. Ann Emerg Med. 1992;21:853-861.

9. Leemon D, Schimelpfenig T. Wilderness injury, illness, and evacuation: National Outdoor Leadership School's incident profiles, 1999-2002. Wilderness Environ Med. 2003;14:174-182.

10. Ela GK. Epidemiology of wilderness search and rescue in New Hampshire, 1999-2001. Wilderness Environ Med. 2004;15:11-17.

11. Montalvo R, Wingard DL, Bracker M, Davidson TM. Morbidity and mortality in the wilderness. West $\mathrm{J} \mathrm{Med.}$ 1998; 168:248-254.

12. Forrester JD, Holstege CP. Injury and illness encountered in Shenandoah National Park. Wilderness Environ Med. 2009;20:318-326.

13. Johnson RM, Huettl B, Kocsis V, Chan SB, Kordick MF. Injuries sustained at Yellowstone National Park requiring emergency medical system activation. Wilderness Environ Med. 2007;18:186-189.

14. Mort A, Godden D. Injuries to individuals participating in mountain and wilderness sports: a review. Clin J Sport Med. 2011;21:530-536.

15. Lareau SA, McGinnis HD. Injuries in mountain bike racing: frequency of injuries in endurance versus cross country mountain bike races. Wilderness Environ Med. 2011;22:222-227,e1-3.

16. Quinn R, Williams J, Bennett B, Stiller G, Islas A, McCord S. Wilderness medical society practice guidelines for spine immobilization in the austere environment. Wilderness Environ Med. 2013;24:241-252.

17. Putukian M. The acute symptoms of sport-related concussion: diagnosis and on-field management. Clin Sports Med. 2011;30:49-61, viii.

18. Maddocks DL, Dicker GD, Saling MM. The assessment of orientation following concussion in athletes. Clin J Sport Med. 1995;5:32-35.

19. Imray C, Wright A, Subudhi A, Roach R. Acute mountain sickness: pathophysiology, prevention, and treatment. Prog Cardiovasc Dis. 2010;52:467-484.

20. Schoene RB. Illnesses at high altitude. Chest. 2008;134: 402-416. 
21. Roach RC, Bärtsch P, Oelz O, Hackett PH. The Lake Louise acute mountain sickness scoring system. In: Sutton JR, Houston CS, Coates G, eds. Hypoxia and Molecular Medicine. Burlington, VT: Queen City Press; 1993: 272-274.

22. Luks AM, McIntosh SE, Grissom CK, et al. Wilderness Medical Society. Wilderness Medical Society consensus guidelines for the prevention and treatment of acute altitude illness. Wilderness Environ Med. 2010;21:146-155.

23. Bennett BL, Hew-Butler T, Hoffman MD, Rogers IR, Rosner MH. Wilderness Medical Society Practice Guidelines for Treatment of exercise-associated hyponatremia. Wilderness Environ Med. 2013;24:228-240.
24. Rogers IR, Hew-Butler T. Exercise-associated hyponatremia: overzealous fluid consumption. Wilderness Environ Med. 2009;20:139-143.

25. Jagoda AS, Bazarian JJ, Bruns JJ Jr, et al. American College of Emergency Physicians; Centers for Disease Control and Prevention. Clinical policy: neuroimaging and decisionmaking in adult mild traumatic brain injury in the acute setting. Ann Emerg Med. 2008;52:714-748.

26. [No authors listed]. The management of minor closed head injury in children. Committee on Quality Improvement, American Academy of Pediatrics. Commission on Clinical Policies and Research, American Academy of Family Physicians. Pediatrics. 1999;104:1407-1415. 